\title{
Insolation driven variations of Mercury's lithospheric strength
}

\author{
Jean-Pierre Williams, ${ }^{1,2}$ Javier Ruiz, ${ }^{3}$ Margaret A. Rosenburg, ${ }^{1}$ Oded Aharonson, ${ }^{1}$ \\ and Roger J. Phillips ${ }^{4}$ \\ Received 31 May 2010; revised 22 September 2010; accepted 14 October 2010; published 21 January 2011.
}

[1] Mercury's coupled 3:2 spin-orbit resonance in conjunction with its relatively high eccentricity of $\sim 0.2$ and near-zero obliquity results in both a latitudinal and longitudinal variation in annual average solar insolation and thus equatorial hot and cold regions. This results in an asymmetric temperature distribution in the lithosphere and a long wavelength lateral variation in lithosphere structure and strength that mirrors the insolation pattern. We employ a thermal evolution model for Mercury generating strength envelopes of the lithosphere to demonstrate and quantify the possible effects the insolation pattern has on Mercury's lithosphere. We find the heterogeneity in lithosphere strength is substantial and increases with time. We also find that a crust thicker than that of the Moon or Mars and dry rheologies for the crust and mantle are favorable when compared with estimates of brittle-ductile transition depths derived from lobate scarps. Regions of stronger and weaker compressive strength imply that the accommodation of radial contraction of Mercury as its interior cooled, manifest as lobate scarps, may not be isotropic, imparting a preferential orientation and distribution to the lobate scarps.

Citation: Williams, J.-P., J. Ruiz, M. A. Rosenburg, O. Aharonson, and R. J. Phillips (2011), Insolation driven variations of Mercury's lithospheric strength, J. Geophys. Res., 116, E01008, doi:10.1029/2010JE003655.

\section{Introduction}

[2] The planet Mercury is locked in a 3:2 spin-orbit resonance making three rotations about its spin axis (sidereal days) every two orbits about the Sun (Figure 1a). Therefore, one diurnal period on the surface of Mercury occurs every 2 years and as a consequence, the Sun is overhead at perihelion in longitudes $0^{\circ}$ and $180^{\circ}$ and at aphelion in longitudes $90^{\circ}$ and $270^{\circ}$. Mercury also possesses a comparatively high eccentricity of 0.20563 , the highest of the planets (Figure $1 \mathrm{~b}$ ). The orbital distance between perihelion and aphelion therefore varies by $23.8 \times 10^{6} \mathrm{~km}(0.1592 \mathrm{AU})$, a variation in solar distance of $\sim 41 \%$. This results in the solar insolation varying from $14,464.4$ to $6279.4 \mathrm{~W} \mathrm{~m}^{-2}$ (a variation $\sim 6 \times$ that of the average solar insolation of Earth). As a result, mean surface temperatures are strongly dependent not only on latitude, but also longitude. Modeling the temperature response of surface and subsurface regolith layers, Vasavada et al. [1999] demonstrate that Mercury should experience a mean longitudinal temperature variation of $\sim 100 \mathrm{~K}$ at the equator, in addition to the latitudinal variation resulting from its near-zero obliquity (Figure 2). Ground-

\footnotetext{
${ }^{1}$ Division of Geological and Planetary Sciences, California Institute of Technology, Pasadena, California, USA.

${ }^{2}$ Ashima Research, Pasadena, California, USA.

${ }^{3}$ Departamento de Geodinámica, Facultad de Ciencias Geológicas, Universidad Complutense de Madrid, Madrid, Spain.

${ }^{4}$ Planetary Science Directorate, Southwest Research Institute, Boulder, Colorado, USA.

Copyright 2011 by the American Geophysical Union. 0148-0227/11/2010JE003655
}

based observations of Mercury's thermal emission reflect this global temperature pattern [Mitchell and De Pater, 1994]. The resulting lateral variation in temperatures will result in long-wavelength heterogeneity in lithosphere strength (e.g., as suggested by McKinnon [1981], Melosh and McKinnon [1988], and Nimmo and Watters [2004]). As the interior of the planet cools and the lithosphere thickens, the discrepancy in lithosphere strength between the hot and cold equatorial thermal regions will increase. In this paper, we quantify and place boundaries on the magnitude of this heterogeneity in lithosphere strength. We couple a thermal evolution model for Mercury [Williams et al., 2007] with the spherical harmonic fit (up to degree and order 90) from Aharonson et al. [2004] of the modeled near-surface temperatures [Vasavada et al., 1999] to account for the insolation pattern in lithosphere evolution (Figure 2). Strength profiles are generated for the resulting thermal profiles and structure for given lithospheric compositions to quantify possible strength variations within the lithosphere [e.g., Ranalli, 1997; Ruiz et al., 2008].

\section{Model}

[3] We utilize the thermal evolution model for Mercury of Williams et al. [2007], previously employed for the Earth [Nimmo et al., 2004] and Mars [Williams and Nimmo, 2004], to explore the planet's evolution in lithospheric strength over time. The energy balance of the mantle and core is described by

$$
H_{\mathrm{m}} M_{\mathrm{m}}-Q_{\mathrm{m}}+Q_{\mathrm{c}}=M_{\mathrm{m}} C_{\mathrm{pm}} \mathrm{d} T_{\mathrm{m}} / \mathrm{d} t
$$



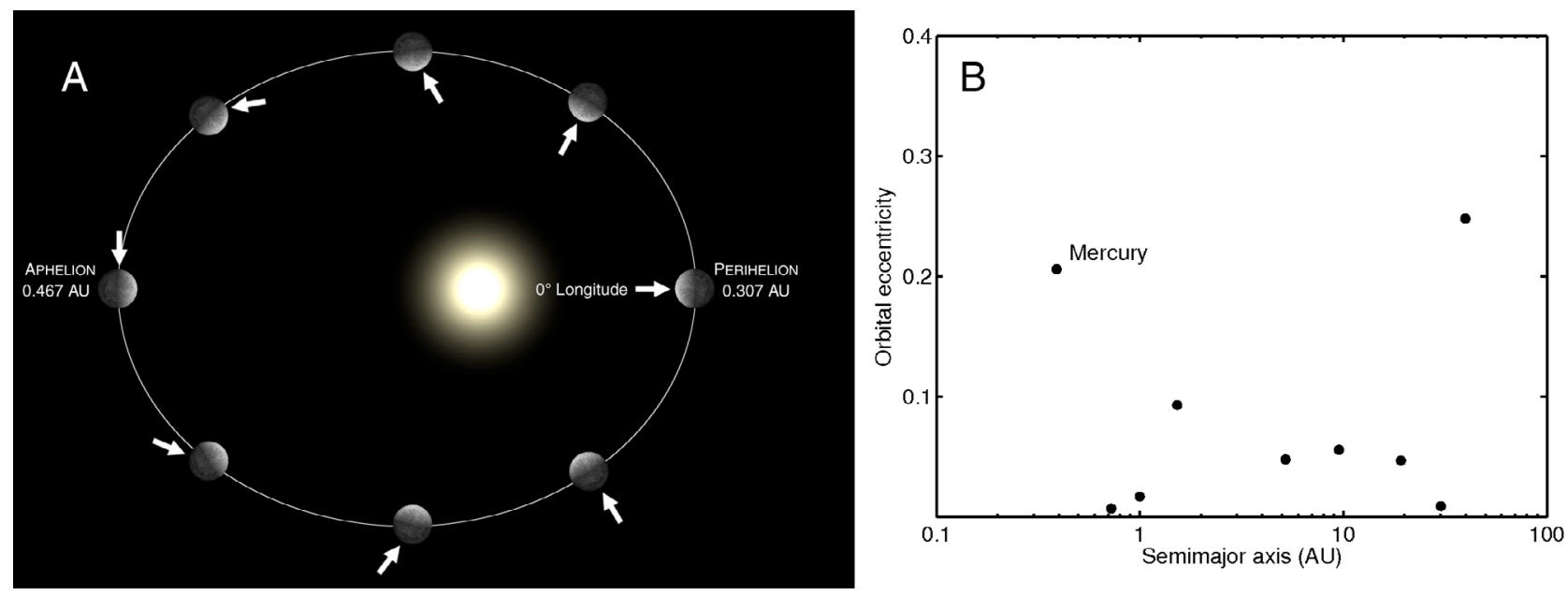

Figure 1. (a) The orbit of Mercury depicting its 3:2 spin-orbit resonance. The white arrows denote the location of $0^{\circ}$ longitude through the orbit. (b) Orbital eccentricities of the planets and Pluto.

and

$$
-Q_{\mathrm{c}}+Q_{1}+Q_{\mathrm{g}}=M_{\mathrm{c}} C_{\mathrm{pc}} \mathrm{d} T_{\mathrm{c}} / \mathrm{d} t
$$

respectively, where subscripts $\mathrm{m}$ and $\mathrm{c}$ denote mantle and core, respectively. The temperature change in the mantle, $\mathrm{d} T_{\mathrm{m}} / \mathrm{d} t$, is determined by internal heating from radioactive decay of elements, $H_{\mathrm{m}} M_{\mathrm{m}}$, where $H$ is the internal heating per unit mass and $M$ is mass, and the exchange of heat across the conductive boundary layers of the $\mathrm{CMB}, Q_{\mathrm{c}}$, and the lithosphere, $Q_{\mathrm{m}}$. Heat flowing from the core to the mantle will reduce the core temperature. If core solidification is occurring, additional heating occurs where $Q_{1}$ is latent heating and $Q_{\mathrm{g}}$ is gravitational heating resulting from the change in gravitational energy from sequestering of lighter elements in the outer liquid core. The quantity $C_{\mathrm{p}}$ is the specific heat capacity $\left(1200\right.$ and $800 \mathrm{~J} \mathrm{~kg}^{-1} \mathrm{~K}^{-1}$ for the mantle and core, respectively [Anderson and Ahrens, 1994]).

[4] The model is adapted here to account for the heterogeneous mean surface temperature distribution and the resulting variation in the conductive boundary layer overlying the mantle. This was accomplished by gridding surface temperatures in $2^{\circ}$ longitudinal/latitudinal bins and calculating heat flux and stagnant lid thickness for each grid element and time step. The total mantle heat loss is then determined. The model employs an exponential temperaturedependent mantle viscosity (Frank-Kamenetskii approximation), $\eta=\eta_{\mathrm{o}} \exp \left[-\gamma\left(T_{\mathrm{m}}-T_{\text {ref }}\right)\right]$, a valid approximation in the stagnant lid regime [Moresi and Solomatov, 1995; Solomatov and Moresi, 1996; Reese et al., 1999; Reese et al., 2005], where $\eta_{\mathrm{o}}$ is the viscosity at a given temperature, $T_{\text {ref }}$, and $\gamma(\sim 0.01)$ is a constant related to the Arrhenius viscosity parameters [Solomatov and Moresi, 1996; Reese et al., 2005]. Viscosity values $\eta_{\mathrm{o}}=10^{20} \mathrm{~Pa} \mathrm{~S}$ and $T_{\text {ref }}=1573 \mathrm{~K}$ are employed here. See Williams et al. [2007] for further discussion on varying the mantle viscosity. For sufficiently large viscosity contrasts, the viscosity of the coldest material at the top becomes large enough that it no longer participates in convective motion and a cold "stagnant lid" develops [Davaille and Jaupart, 1993; Solomatov, 1995; Moresi and
Solomatov, 1995; Solomatov and Moresi, 1996; Trompert and Hansen, 1998; Grasset and Parmentier, 1998]. The large temperature differences experienced by planetary mantles imply that they operate in such a stagnant-lid regime (excluding the Earth, which may be a consequence of water availability [e.g., Regenauer-Lieb et al., 2001]) with large viscosity contrasts occurring in the cold boundary layer and near-isoviscous convection in the active part of the mantle beneath. Convection penetrates the upper boundary by a small length determined by the exponential growth of the viscosity [Solomatov, 1995]. The thickness of this rheological sublayer is $\delta_{\mathrm{rh}} \sim \delta_{\mathrm{o}} /(\gamma \Delta T)$ where $\delta_{\mathrm{o}}$ is the total upper boundary layer thickness with a temperature drop $\Delta T$. Only the small temperature difference across the rheological layer, $\Delta T_{\mathrm{rh}} \sim \gamma^{-1}$, is available to drive convection in the underlying region as the immobile lid has no fluid dynamic role. Convection therefore depends on the rheological gradient $-\mathrm{d} \ln (\eta) / \mathrm{d} T_{\mathrm{m}}$ and will be a function of the rheological law of

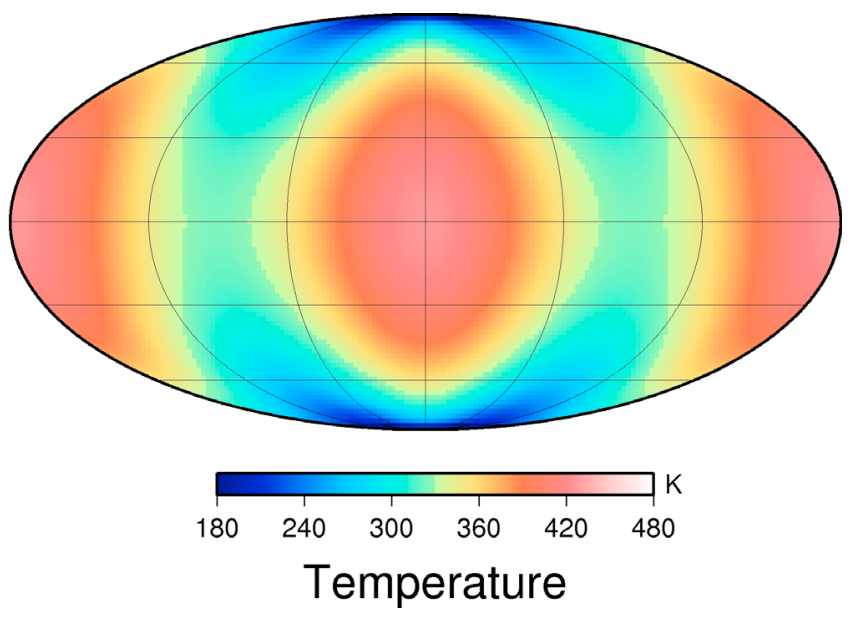

Figure 2. The global spherical harmonic fit from Aharonson et al. [2004] of the near-surface regolith temperatures derived from the two-layer model of Vasavada et al. [1999]. Longitudes $0^{\circ}$ and $180^{\circ}$ are at the center and edges of the temperature map. 

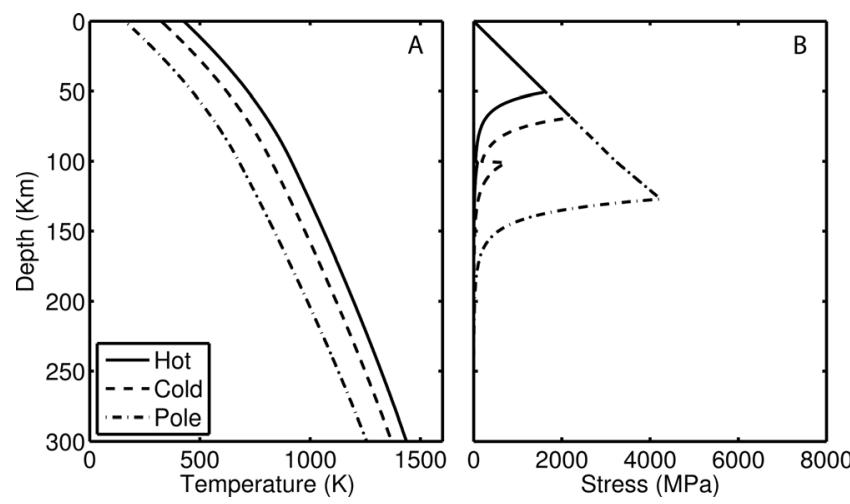

Figure 3. Present-day (a) temperature profiles and (b) corresponding compressive strength envelopes for the upper portion of the stagnant lid for the nominal model. The three locations depicted are the hot and cold equatorial thermal poles $\left(0^{\circ} / 180^{\circ}\right.$ and $90^{\circ} / 270^{\circ}$ longitude, respectively) and the rotation pole $\left(90^{\circ} /-90^{\circ}\right.$ latitude)

the fluid and the interior temperature of the mantle, not the surface temperature of the planet. The stagnant lid heat flow is well approximated in these circumstances by [e.g., Solomatov and Moresi, 2000; Nimmo and Stevenson, 2000]

$$
F_{\mathrm{s}}=a k\left(\frac{\rho_{\mathrm{m}} g \alpha}{\kappa \eta\left(T_{\mathrm{m}}\right)}\right)^{\frac{1}{3}} \gamma^{-\frac{4}{3}}
$$

where $k$ is the thermal conductivity, $\kappa$ is thermal diffusivity, $\rho_{\mathrm{m}}$ is mantle density, $g$ is gravitational acceleration, $\alpha$ is the coefficient of thermal expansion, and $a(=0.53)$ is a dimensionless constant [Solomatov and Moresi, 2000]. As can be seen, the heat flow depends on the mantle temperature through the temperature dependence of the viscosity and is independent of the overall temperature difference between the convecting interior and the surface or the thickness of the total mantle. This is because convective instabilities are determined solely by local conditions in the boundary layer. Since $F_{\mathrm{s}}$ is also given by $k \Delta T / \delta_{\mathrm{o}}$ we find

$$
\frac{\delta_{\mathrm{o}}}{\Delta T}=\left(\frac{\rho_{\mathrm{m}} g \alpha}{\kappa \eta\left(T_{\mathrm{m}}\right)}\right)^{-\frac{1}{3}} \gamma^{\frac{4}{3}}
$$

and

$$
\delta_{\mathrm{rh}}=\left(\frac{\rho_{\mathrm{m}} g \alpha}{\gamma \kappa \eta\left(T_{\mathrm{m}}\right)}\right)^{-\frac{1}{3}}
$$

Therefore, the thermal boundary layer thickness $\delta_{\mathrm{rh}}$ will depend on the mantle temperature and rheological gradient, the stagnant lid thickness, $\delta_{\mathrm{o}}$, however will depend on surface temperature.

[5] Whether the mantle is currently convecting or in a purely conductive regime is not clear and a matter of debate [e.g., Breuer et al., 2007; Redmond and King, 2007]. Because of a lack of knowledge regarding many of the parameters, it is difficult to robustly predict the state of the mantle however the presence of a weak magnetic field, assuming a core dynamo origin, provides supporting evidence for present-day mantle convection to generate the required heat flux from the core to sustain a dynamo [Redmond and King, 2007; Williams et al., 2007]. The observational evidence for wide spread, possibly basaltic volcanism extending later into Mercury's history than previously thought, as seen by MESSENGER [Denevi et al., 2009; Lawrence et al., 2010; Prockter et al., 2010], also implies mantle convection occurred in Mercury's past providing the partial melt from adiabatic decompression to generate basaltic magmas. Because of the ambiguity in the present state of the mantle, the model checks to see if the maximum extent of the stagnant-lid in addition to the thermal boundary layer thickness at the core-mantle boundary (CMB) becomes comparable to total mantle thickness. In these circumstances, the model assumes convection is no longer occurring globally and treats the mantle as purely conductive layer. This occurs in a small subset of our model runs.

[6] Incompatible elements, such as the long-lived radioactive nuclides ${ }^{40} \mathrm{~K},{ }^{232} \mathrm{Th},{ }^{235} \mathrm{U}$, and ${ }^{238} \mathrm{U}$, are the primary source of heat generation in the mantle and thus their concentrations and distribution influence the mantle cooling history. These elements tend to preferentially differentiate into the crust due to their affinity for melt [e.g., Philpotts and Schnetzler, 1970; Hauri et al., 1994; Blundy and Wood, 2003]. The resulting elevated concentration of heat-producing elements in the crust relative to the mantle reduces the driving energy for convection within the mantle. The temperature-dependency of the viscosity regulates the mantle temperature and the reduction in internal heating results in an increase in the viscosity to compensate. Except for the initial period of time in the early stage where the mantle cools rapidly to remove excess primordial heat, the mantle temperature changes very little and the interior primarily cools by thickening of the lithosphere. Therefore, the fractionation of radiogenic elements into the crust also results in a thicker lithosphere. Following Breuer and Spohn [2003], we account for the transfer of mantle heat sources to the crust by multiplying the heat production density in the mantle by a factor, $1-\Lambda\left(V_{\mathrm{c}} / V_{\mathrm{m}}\right)$, where $V_{\mathrm{c}}$ and $V_{\mathrm{m}}$ are the volumes of the crust and mantle, respectively, and $\Lambda$ is the radiogenic element enrichment factor. We select a value of 2 for the nominal model, which ensures some radiogenic elements remain in the mantle for a crust $100 \mathrm{~km}$ thick. We run models with $\Lambda=1$ and 4 as end members with equal partitioning of radiogenic elements in the crust and mantle and nearly the entirety of radiogenic elements partitioned into the crust, respectively.

\section{Lithosphere Strength}

[7] We utilize the modeled heat flux (equation (3)) at the base of the stagnant lid to determine the thermal profile in the lithosphere for a given surface temperature, accounting for the preferential partitioning of radiogenic elements into the crust, to determine the variation in lithospheric strength with depth [e.g., Ranalli, 1997; Ruiz et al., 2008, 2009]. These strength envelopes provide a means of comparing lithosphere strength between the hot and cold regions of Mercury's surface (Figure 3).

[8] The strength of the lithosphere is determined by the brittle and ductile properties of its constitutive rocks. The shallow lithosphere, where temperatures and confining 
pressures are relatively low, is characterized by brittle behavior [Byerlee, 1968] resulting in a yield stress that increases linearly with depth $z$ and is independent of rock type and surface conditions [Byerlee, 1978]. The brittle strength is the deviatoric stress necessary to overcome lithospheric strength, which for zero pore pressure is given by

$$
\begin{gathered}
\left(\sigma_{1}-\sigma_{3}\right)_{b}=\beta g \rho_{c} z, \text { for } z<b_{c} \\
\left(\sigma_{1}-\sigma_{3}\right)_{b}=\beta g\left[\rho_{c} b_{c}+\rho_{m}\left(z-b_{c}\right)\right], \text { for } z>b_{c}
\end{gathered}
$$

where $\beta$ is a coefficient depending on the stress regime which is 3 for pure compression [Ranalli, 1997], $\rho_{\mathrm{c}}$ is the crust density, and $b_{\mathrm{c}}$ is the thickness of the crust. We focus on compression here for its relevance to lobate scarp formation. The gravity $g$ is $3.7 \mathrm{~m} \mathrm{~s}^{-2}$, and we assume crust and mantle densities of 2900 and $3400 \mathrm{~kg} \mathrm{~m}^{-3}$, respectively.

[9] At higher temperatures, characteristic of the lower portions of the lithosphere, ductile behavior dominated by the creep of the main constituent becomes the strengthlimiting factor. Ductile strength strongly decreases with temperature and hence depth and can be described by a thermally activated power law [Burov and Diament, 1992; Ranalli and Murphy, 1987; Mackwell et al., 1990],

$$
\left(\sigma_{1}-\sigma_{3}\right)_{d}=\left(\frac{\dot{e}}{A}\right)^{1 / n} \exp \left(\frac{Q}{n R T}\right),
$$

where $\dot{e}$ is the strain rate, $A$ and $n$ are material constants, $Q$ is the activation energy of creep, and $R$ is the gas constant (8.31447 $\mathrm{J} \mathrm{mol}^{-1} \mathrm{~K}^{-1}$ ). The strength is determined by the weakest rheology at the respective depth for a given stress difference. The brittle-ductile transition (BDT) occurs where the strengths of the two deformation mechanisms are equal and is the strongest portion of the lithosphere. Ultramafic minerals characteristic of mantle rocks have considerably higher creep resistance than those of a more silica-rich crust and depending on crustal depth and thermal gradient, one or more strength maxima may exist [Ranalli, 1997]. On Earth, the continents are characterized by a multilayer composition and rheology and may contain more than one BDT [Ranalli and Murphy, 1987; Burov and Diament, 1995].

[10] The total strength of the lithosphere is defined as the integrated strength over depth,

$$
S=\int_{0}^{T_{\mathrm{m}}}\left(\sigma_{1}-\sigma_{3}\right)(z) \mathrm{d} z
$$

from the surface to a depth $T_{\text {mech }}$ corresponding to a depth at which the strength reaches a low value defining the mechanical thickness of the lithosphere, typically taken to be in the range 10-50 MPa [McNutt, 1984; Ranalli, 1994; Ruiz et al., 2008]. A value of $10 \mathrm{MPa}$ is adopted here as being more appropriate for the low gravity of Mercury [Ruiz et al., 2006]; however, results are not sensitive to the exact value used due to the exponential dependence on ductile strength of temperature.

[11] The strength is related to the effective elastic thickness $T_{\mathrm{e}}$ derived from modeling the flexure of elastic plates and shells. $T_{\mathrm{e}}$ is useful in that it is a measurable quantity, for example, by admittance or flexural studies [e.g., Watts, 2001]. $T_{\text {mech }}$ and $T_{\mathrm{e}}$ coincide when there is negligible lithosphere curvature (i.e., zero bending moment), whereas increased curvature results in yielding of the lithosphere and a reduction in $T_{\mathrm{e}}$ relative to $T_{\text {mech }}$. Therefore, $T_{\mathrm{e}}$ reflects the integrated brittle, ductile, and elastic strength of the lithosphere, rather than a specific geotherm or physical boundary at depth and can be related to $S$ for a given lithospheric curvature [e.g., McNutt, 1984; Watts and Burov, 2003]. The value of $T_{\text {mech }}$ therefore represents an upper limit for $T_{\mathrm{e}}$. We determine elastic thickness of the individual crust and mantle layers, $T_{\mathrm{e}, \mathrm{c}}$ and $T_{\mathrm{e}, \mathrm{m}}$, assuming they are equivalent to the mechanical thickness of the layers (i.e., zero curvature). The effective elastic thickness for the entire lithosphere then depends on whether the crustal and mantle layers are coupled or separated by an incompetent lower crustal layer. If $T_{\mathrm{e}, \mathrm{c}}$ equals the crust thickness and no layer of weak, incompetent lower crust exists, then the lithosphere acts as a single plate and $T_{\mathrm{e}}=T_{\mathrm{e}, \mathrm{c}}+T_{\mathrm{e}, \mathrm{m}}$. If the crust and mantle lithosphere are decoupled, then $T_{\mathrm{e}}=\left(T_{\mathrm{e}, \mathrm{c}}^{3}+T_{\mathrm{e}, \mathrm{m}}^{3}\right)^{1 / 3}$ [e.g., Burov and Diament, 1995].

[12] The strain rate during Mercury's history is unknown, but strain rates of $10^{-16}$ and $10^{-19} \mathrm{~s}^{-1}$ are used in the calculations, based on a range usually considered for terrestrial planets [e.g., McGovern et al., 2002]. The cumulative contractional strain extrapolated globally $(\sim 0.1 \%)$ implies an average stain rate over the last 4 Gyr of $\sim 10^{-20} \mathrm{~s}^{-1}$ [e.g., Hauck et al., 2004]. Strain rates associated with geologic processes such as compression and extension, mantle convection, or impacts will produce higher values. A strain rate of $10^{-16} \mathrm{~s}^{-1}$ is typical for terrestrial intraplate deformation in relatively active regions [e.g., Tesauro et al., 2007], whereas the lower value, $10^{-19} \mathrm{~s}^{-1}$, is frequently estimated for thermal contraction on terrestrial planets [e.g., Schubert et al., 1988; Anderson and Grimm, 1998]. Nimmo and Watters [2004] and Zuber et al. [2010] adopt $10^{-17} \mathrm{~s}^{-1}$ as a likely upper bound for Mercury at the time of lobate scarp formation.

[13] Mercury is generally thought to be deficient in interior volatiles, and prior to MESSENGER observations, lunar highland anorthosite was considered a likely analogue for the composition of the surface [Blewett et al., 2002]. MESSENGER neutron spectrometer observations however are not consistent with such a composition [Lawrence et al., 2010] and growing evidence for extensive volcanic resurfacing [Head et al., 2008; Prockter et al., 2010] would suggest a basaltic composition for the crust may be more appropriate. Further, the crust reflectance indicates a heterogeneous olivine- or pyroxene-rich crustal lithology rather than a dominantly anorthositic crust [Denevi et al., 2009]. For creep parameters, we use flow laws of dry Maryland diabase [Mackwell et al., 1998], which is pyroxene-rich and therefore provides a possible basaltic analog for the mercurian crust, and dry dunite [Chopra and Paterson, 1984] for the lithospheric mantle. We also include the rheology of dry anorthite [Rybacki and Dresen, 2000] for the crust for comparison. On the other hand, evidence for explosive volcanism suggests the presence of volatiles in Mercury's interior [Kerber et al., 2009], and for this reason we also explore the case with wet Maryland diabase [Caristan, 1982] and wet dunite [Chopra 

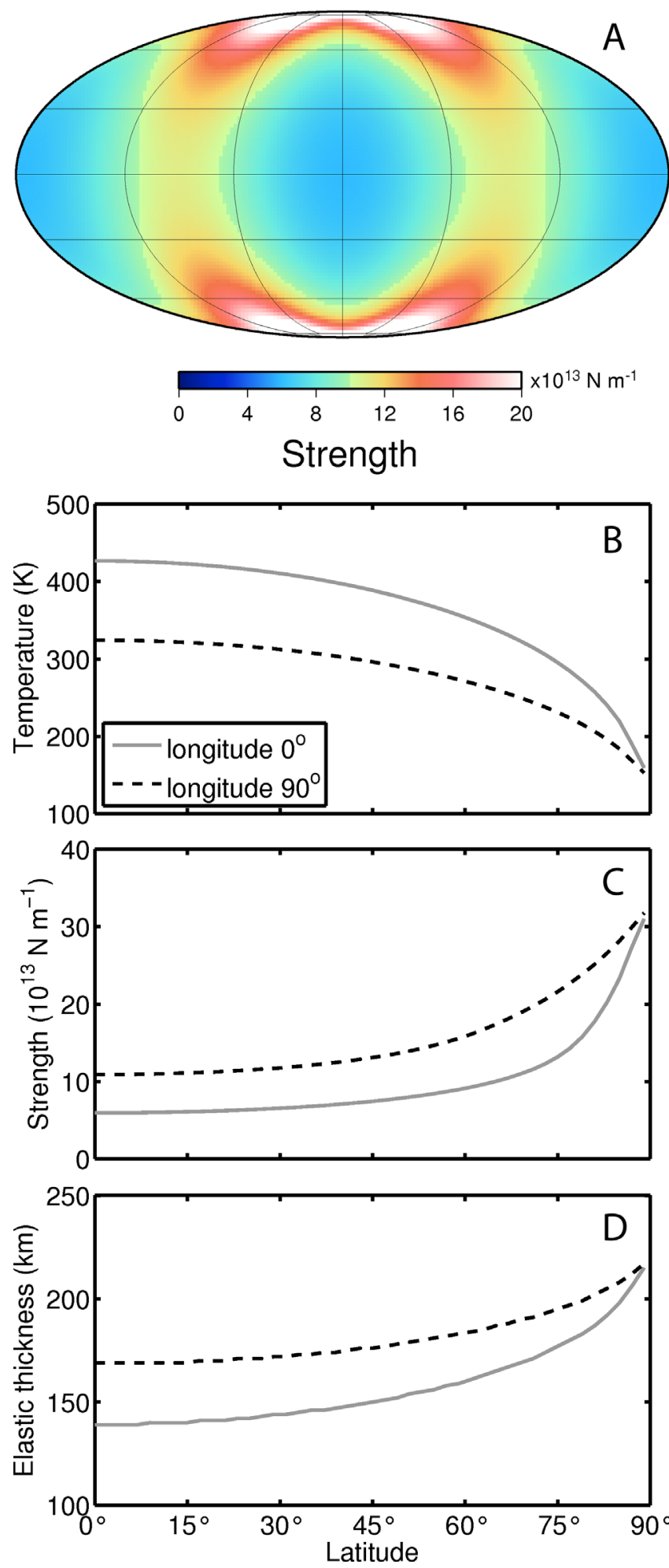

Figure 4. (a) Map of present-day lithospheric strength derived from the nominal model. Longitudes $0^{\circ}$ and $180^{\circ}$ are at the center and edges of the map. The variation in strength is the results of the variation in average nearsurface temperatures (Figure 2). (b) Latitudinal temperature profiles centered on a "hot" pole $\left(0^{\circ} / 180^{\circ}\right.$ longitude) and a "cold" pole $\left(90^{\circ} / 270^{\circ}\right.$ longitude), (c) the corresponding latitudinal strength profiles, and (d) the effective elastic thicknesses. and Paterson, 1984] rheologies for the crust and lithospheric mantle.

\section{Results}

\subsection{Nominal Model}

[14] The results of our nominal model are shown in Figure 4 showing the present-day lateral variation in total integrated lithosphere strength (equation (8)) and Figure 5 depicting the compressive yield strength envelope over time by combining the brittle and ductile deformation laws into a strength profile of the lithosphere. We run the model for 4.6 Gyr assuming Mercury acquired its current rotational and orbital state rapidly on a short time scale relative to the overall history of the planet. The mantle temperature and heat flow is high during the first few hundred million years [Williams et al., 2007] from the rapid loss of primordial heat as the mantle adjusts to a self-regulated state [Schubert et al., 2001]. The exact time that we assume Mercury initially acquired its current spin-orbit resonance during this early phase of rapid heat loss and vigorous mantle convection should not significantly alter the results.

[15] This model employs a dry diabase and olivine rheology for the crust and mantle, respectively, and a strain rate of $10^{-19} \mathrm{~s}^{-1}$. We assume a crust thickness of $100 \mathrm{~km}$ based on constrains placed by relaxation studies [Nimmo, 2002], fault depth estimates [Nimmo and Watters, 2004], and geodetic estimates [Anderson et al., 1996; Smith et al., 2010].

[16] Our nominal model assumes a Th-rich and U- and $\mathrm{K}$-poor concentration of heat-producing elements based on a bulk composition model resulting from late-stage silicate vaporization [Fegley and Cameron, 1987] that predicts $400 \mathrm{ppb} T \mathrm{Th}$ and negligible concentrations of $\mathrm{U}$ and $\mathrm{K}$ (for example, see Table 2 of Hauck et al. [2004]). Lobate scarps, interpreted to be the surface expression of blind thrust faults observed in Mariner 10 [Strom et al., 1975] and MESSENGER images [Solomon et al., 2008], imply 1-2 km of radial contraction have occurred since the end of the late heavy bombardment [Watters et al., 2009]. This places a severe limit on the amount of global contraction Mercury has experienced. The large half-life of ${ }^{232} \mathrm{Th}$ of $14 \mathrm{Gyr}$ results in a lower rate of cooling and thus less contraction of the planet relative to a model containing significant amounts of $\mathrm{U}$ and $\mathrm{K}$, making such a model favorable [Hauck et al., 2004].

[17] The concentration of a light alloying element, sulfur being the most reasonable candidate, has a significant influence on the thermal history of the interior and state of the core [e.g., Hauck et al., 2004; Williams et al., 2007]. Sulfur substantially depresses the Fe-S eutectic inhibiting core solidification [Boehler, 1996; Fei et al., 1995, 1997, 2000; Chen et al., 2008]. Our nominal model includes an initial core sulfur concentration of $3 \mathrm{wt} \%$. Additional model parameters are those of Williams et al. [2007].

[18] The strength and effective elastic thickness of the lithosphere is found to vary substantially depending on latitude and longitude due to the average surface insolation pattern (Figure 4). The near-zero obliquity of the planet results in perpetually cold surface temperatures in the polar regions $(\sim 150 \mathrm{~K})$, and the 3:2 spin-orbit resonance coupled with the relatively high eccentricity results in $\sim 100 \mathrm{~K}$ 


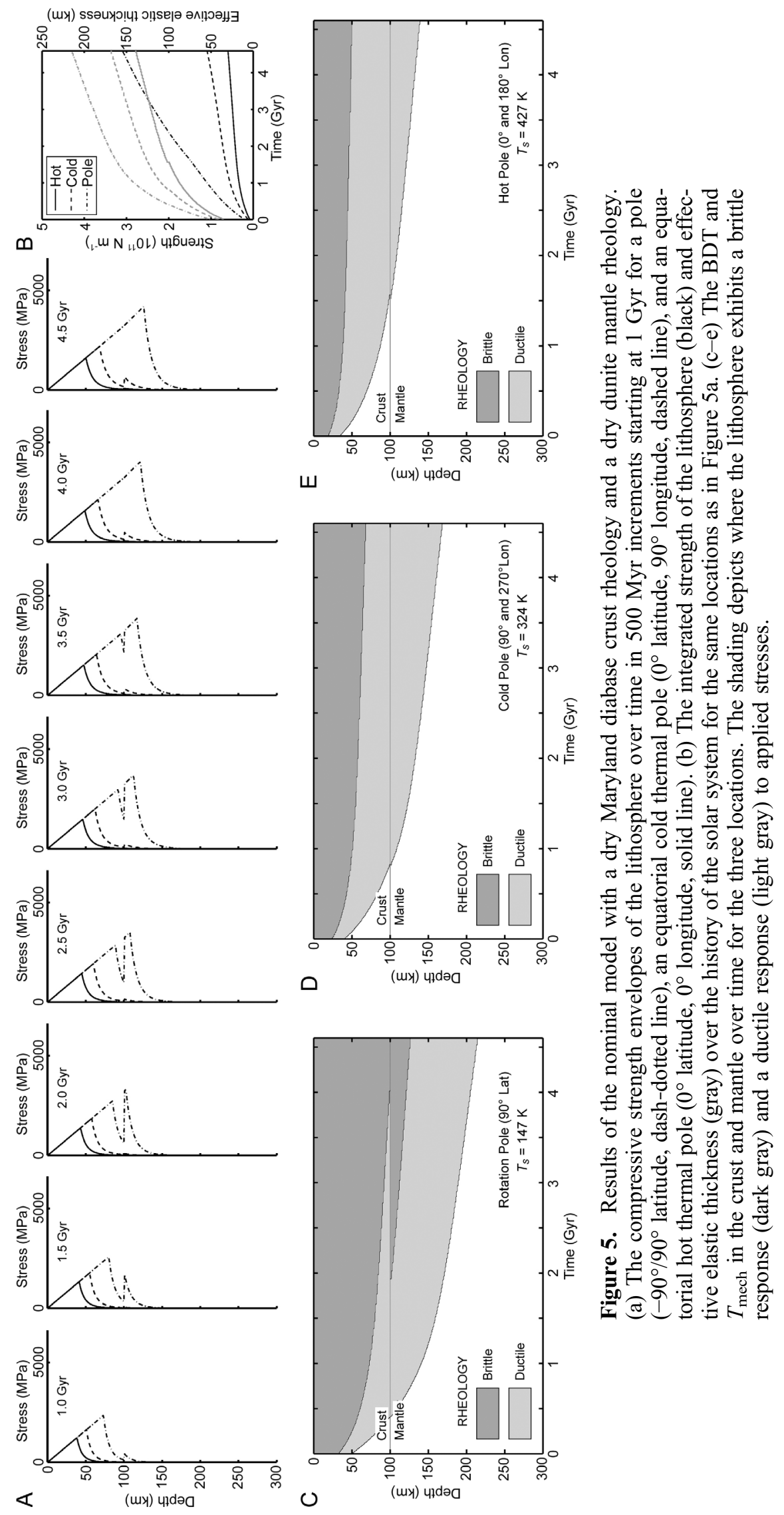


average temperature difference between $0^{\circ}$ and $180^{\circ}$ longitudes and $90^{\circ}$ and $270^{\circ}$ longitudes, referred to as the "hot" and "cold" equatorial poles. These discrepancies grow with time (Figure 5), indicating that any manifestation of this lithospheric heterogeneity would be more apparent later in the planet's history. The depth to the BDT and $T_{\text {mech }}$ also varies considerably with present-day values for the hot equatorial poles of 50 and $139 \mathrm{~km}$, respectively, the cold equatorial pole of 68 and $169 \mathrm{~km}$, respectively, and the polar region of 127 and $215 \mathrm{~km}$, respectively. Such a large value for $T_{\text {mech }}$ in the polar region, occupying possibly more than a third of the mantle thickness, implies the mantle beneath the polar regions contain very thin permissible depths of convection. The dry rheology results in coupled crust and mantle lithospheres that act as a single layer, and therefore $T_{\text {mech }}$ is equivalent to $T_{\mathrm{e}}$ for a lithosphere with negligible curvature.

[19] The nominal model is one representative scenario. As many of the parameters are only crudely constrained, a full exploration of the parameter space at this time is of limited utility. However, we discuss further how varying relevant parameters influences the results, although regardless of the parameters chosen, the overall lateral heterogeneity of the lithosphere structure does not change.

\subsection{Parameter Variations}

[20] Prior to MESSENGER observations, the crust of Mercury was considered to be anorthositic in composition similar to the lunar highlands. Figure 6 shows model results with a dry anorthite crustal rheology [Rybacki and Dresen, 2000]. The stronger crustal rheology results in a deeper BDT with the exception of the polar region where the BDT is in the mantle in the latter half of the planet's history resulting in identical present-day lithosphere strengths. The $\mathrm{BDT}$ in the equatorial region however remains in the crust for the entirety of the planet's history resulting in a stronger present-day lithosphere $(51 \%$ and $64 \%$ stronger at the cold and hot equatorial poles, respectively) in spite of the fact that the mechanical thickness, which is in the mantle, remains the same. The discrepancy between these models therefore is largely in the equatorial region where the weaker diabase crustal rheology results in a larger latitudinal strength variation than the anorthosite crust model. The two crustal dry rheologies result in small differences in total lithosphere strength relative to a volatile-rich interior that can alter the results substantially. Figure 7 shows results using wet crustal [Caristan, 1982] and mantle rheologies [Chopra and Paterson, 1984]. The consequence is a considerable reduction in crust strength. This leads to a relatively thin, weak lithosphere globally for $2 \mathrm{Gyr}$ and a perpetually weak lithosphere in the equatorial region with limited mantle strength and effective elastic thickness. Further, the crust and mantle are decoupled with a weak, ductile lower crust for significant portions of the planet's history with the equatorial region remaining decoupled presently. Crust-mantle decoupling results in a drastic reduction in the effective elastic thickness, by a factor of $\sim 2$, and is no longer characterized by a single mechanical layer. The strength of the lithosphere significantly increases once the mantle begins to contribute strength seen as jumps in $T_{\mathrm{e}}$ in Figure $7 \mathrm{~b}$. This enhances the variability of $T_{\mathrm{e}}$ with location as these upward steps in $T_{\mathrm{e}}$ occur at different times for different surface temperatures resulting in potentially large differences early in the planet's history. Additionally, the polar region experiences a large jump in $T_{\mathrm{e}} \sim 4 \mathrm{Gyr}$ as the crust and mantle lithosphere become coupled (Figure 7). From this, it is clear that the interior volatile content plays a dominant role in the strength of the lithosphere.

[21] If the strain rates are higher than assumed in our nominal model, then the lithosphere will be stronger. Taking a value of $10^{-16} \mathrm{~s}^{-1}$ as the higher acceptable value, the BDT depth increases $\sim 10 \mathrm{~km}$ globally for a lithosphere age of 1 Gyr, approximately when many of the lobate scarps and smooth plains material formed. Conversely, employing a smaller strain rate such as $10^{-20} \mathrm{~s}^{-1}$ as implied by the $\sim 0.1 \%$ net global strain at the surface from the lobate scarps over the last 4 Gyr, would result in a shallower BDT. The effect of changing the strain rate by an order of magnitude on the results however, as Nimmo and Watters [2004] have demonstrated, is relatively minor.

[22] The concentration of sulfur in the core can have a significant influence on the thermal history of Mercury's interior [Hauck et al., 2004; Williams et al., 2007]. Increasing the core S content reduces the eutectic temperature of the Fe-S liquid core, delaying the onset of core solidification, and leading to a smaller solid inner core and thus, less latent and gravitational heating [Williams et al., 2007]. Early in the planet's history, prior to core solidification, the lithosphere strength is unaffected. For example, doubling the $\mathrm{S}$ content from 3 to $6 \mathrm{wt} \%$ has no effect on lithosphere strength at $1 \mathrm{Gyr}$. The reduction in core heating however results in a presentday mantle that is cooler and purely conductive. Therefore, whether the present-day mantle convects with higher concentrations of $\mathrm{S}$ in the core will depend on the crust thickness and the extent of partitioning of radiogenic elements into the crust.

[23] Changing the concentrations of radiogenic elements, the radiogenic element enrichment factor $\Lambda$ (section 2), or the crust thickness, effects the distribution of heat sources in the planet and thus the temperature profile in the lithosphere. Decreasing $\Lambda$ reduces partitioning of incompatible elements into the crust. Heat production is decreased in the crust and increased in the mantle. This results in a stronger lithosphere especially early in the planet's history as the crust is cooler. For example, setting the distribution of radiogenic elements to be equal in the crust and mantle increases the BDT depth by $\sim 8 \mathrm{~km}$ globally and the integrated strength by $25 \%$ and $36 \%$ for the coldest and hottest surface temperatures, respectively, at 1 Gyr. In the hot equatorial region, $T_{\text {mech }}$ occurs in the crust and therefore also increases by $8 \mathrm{~km}$. However, at the pole, $T_{\text {mech }}$ decreases by $2 \mathrm{~km}$ despite the lithosphere being stronger as $T_{\text {mech }}$ occurs in the mantle where heat production is increased. The resulting presentday lithosphere is also stronger in the equatorial region than the nominal model; however, the polar region with a present-day BDT in the mantle is moderately weaker $(5 \%)$ due to the warmer underlying mantle lithosphere resulting in reduced latitudinal variation in lithosphere strength than models with greater partitioning. Conversely, setting $\Lambda=4$ exaggerates the latitudinal strength difference as the colder mantle lithosphere results in a much deeper mechanical thickness in the polar region, $286 \mathrm{~km}$, an increase of $71 \mathrm{~km}$ relative to the $\Lambda=2$ model. The mantle is also in a conductive regime after $\sim 2$ Gyr. 


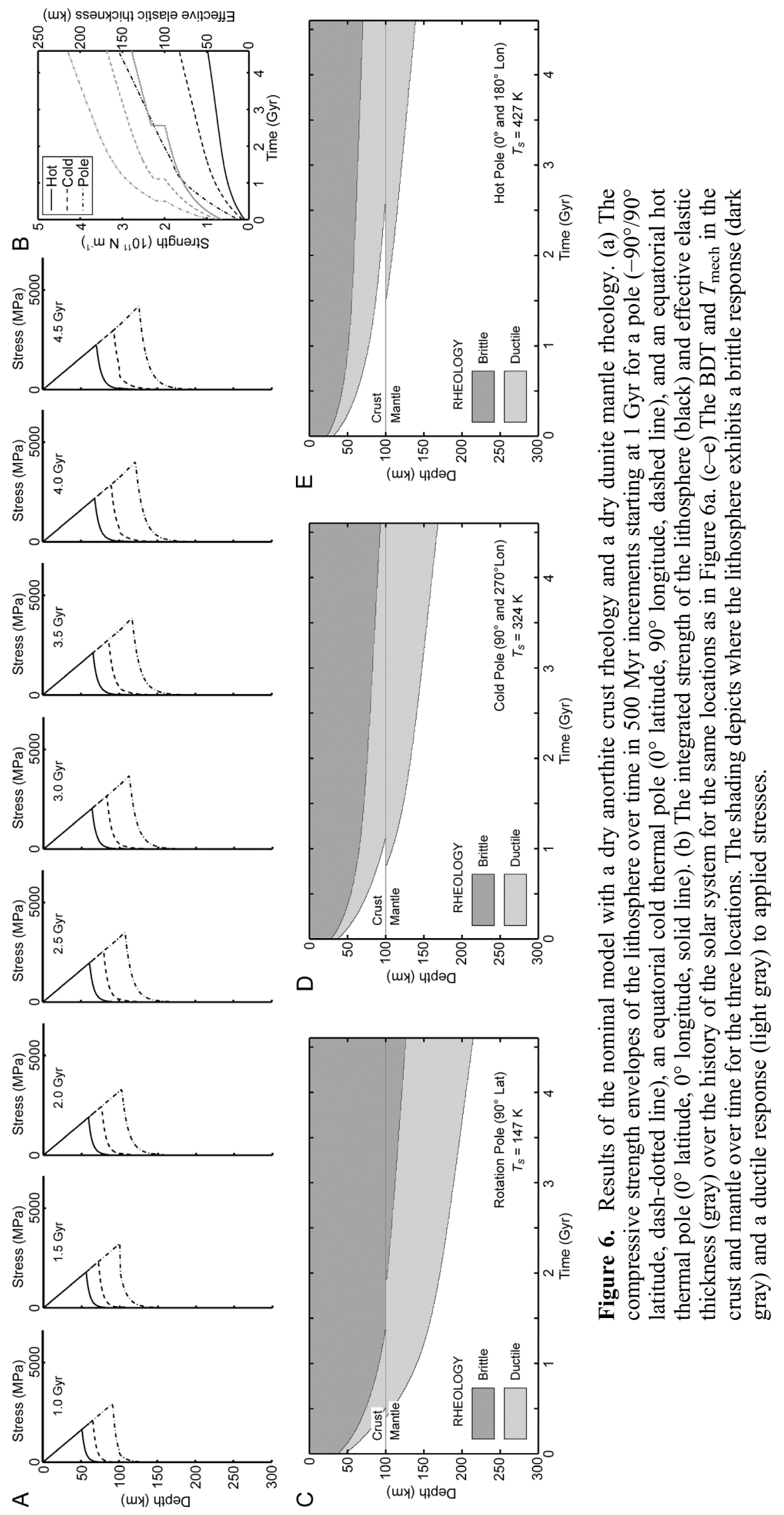




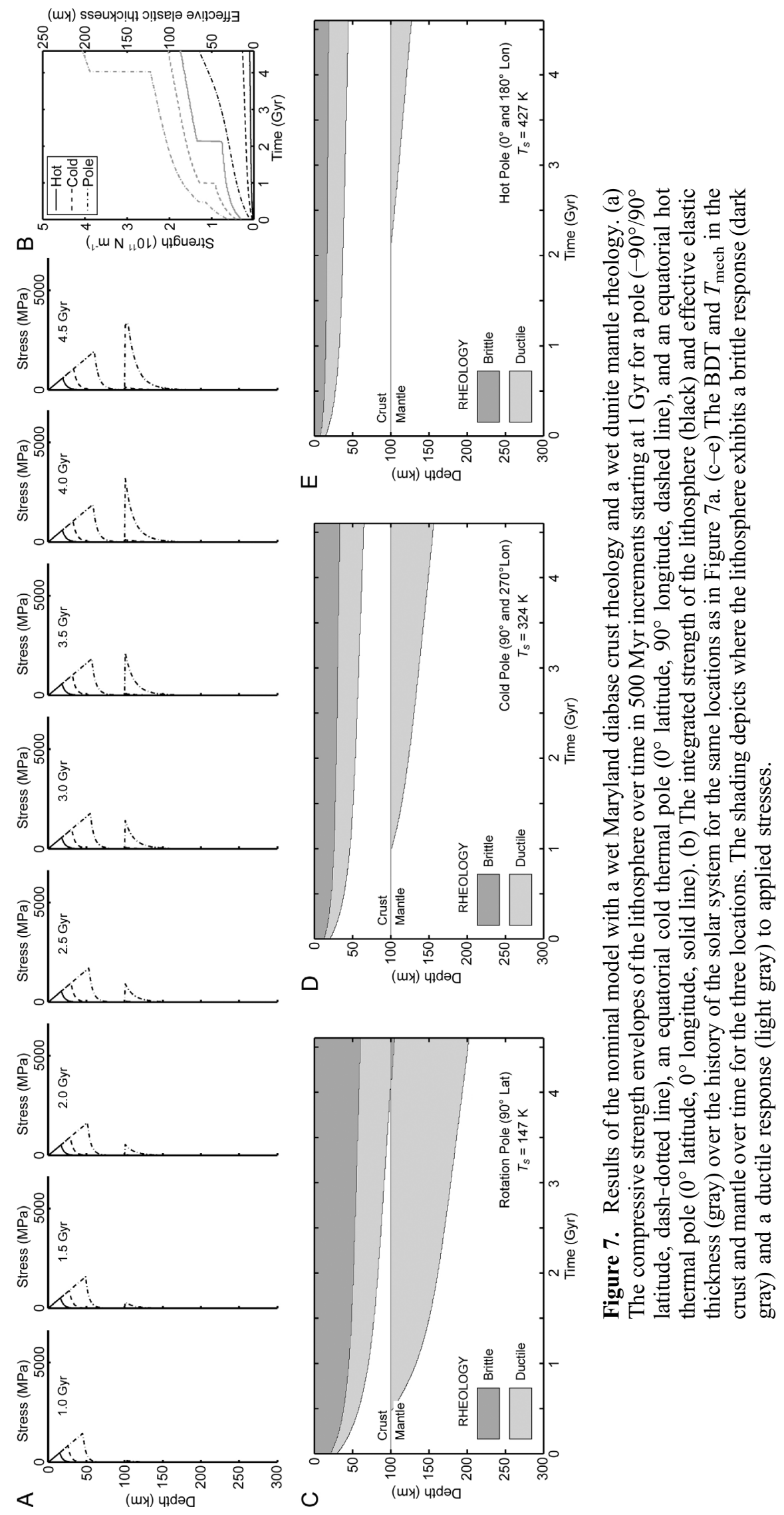


[24] Altering the concentrations of heat producing elements has a similar effect on the results as changing $\Lambda$. For example, assuming a CI chondrite composition consistent with a formation history that included a giant impact event that stripped off much of the outer, silicate-rich layer of the planet [Lodders and Fegely, 1998; Cameron et al., 1988], we employ a model with $550 \mathrm{ppm} \mathrm{K}$ with smaller concentrations of $\mathrm{Th}$ and $\mathrm{U}$ of 30 and $8 \mathrm{ppb}$, respectively. The half-life of ${ }^{40} \mathrm{~K}$ is an order of magnitude smaller than ${ }^{232} \mathrm{Th}$ resulting in more heat generation early in the planet's history. However, the longer half life of Th provides a sustained internal heating that exceeds the heat generated by $\mathrm{K}$ in the latter half of the planet's history. Therefore at $1 \mathrm{Gyr}$, $T_{\text {mech }}$ of the lithosphere decreases 15 and $23 \mathrm{~km}$ at the hot equatorial and rotation poles, respectively, relative to the nominal model, but the present-day $T_{\text {mech }}$ increases 45 and $53 \mathrm{~km}$ at the corresponding poles relative to the nominal model reflecting the reduced present-day internal heating. This relates to a $147 \%$ increase in present-day lithosphere strength at the hot equatorial pole relative to the nominal model. The significantly increased present-day lithosphere strength at the hot pole reflects a reduction in the discrepancy between the polar regions and the equatorial regions in this model due to the mantle lithosphere contributing more to the strength in the equatorial latitudes. The reduction in radiogenic heating in the latter half of the planet's history also results in a conductive mantle during the last Gyr.

[25] A reduction in crust thickness reduces the volume of enrichment and fewer radiogenic isotopes are partitioned out of the mantle. The corresponding hotter mantle results in a weaker mantle lithosphere. A crust thickness of $50 \mathrm{~km}$, a value accordant with that of the Moon [Wieczorek et al., 2006; Hikida and Wieczorek, 2007; Ishihara et al., 2009] and Mars [Zuber et al., 2000; Neumann et al., 2004; Wieczorek and Zuber, 2004], results in a stronger lithosphere in the polar region and at the cold equatorial thermal pole early in the planets history as the BDT extends into the mantle earlier; however in the hot equatorial region, the BDT remains within the crust resulting in a weaker lithosphere and an enhancement of the longitudinal strength variation. The warmer mantle eventually leads to a reduction in present-day lithosphere strength in the polar region reducing the latitudinal variation in strength.

[26] While far from an exhaustive exploration of all possible parameters, this study shows that variations in several parameters can lead to significant variations in lithosphere strength. Since many of these parameters are poorly constrained, further observations by the current MESSENGER [Solomon et al., 2001] and future BepiColombo [Anselmi and Scoon, 2001; Grard and Balogh, 2001] missions are needed to further constrain the properties of the lithosphere. The solar insolation-induced heterogeneity of the lithosphere strength, however, persists regardless of the parameters chosen. The choice of parameters does little to mitigate the difference, and therefore it should be anticipated that the polar regions of the planet should be characterized by a stronger lithosphere than the equatorial region and, to a lesser extent, the cooler equatorial regions (centered on $90^{\circ}$ and $270^{\circ}$ longitude) to be stronger than the hotter equatorial regions (centered on $0^{\circ}$ and $180^{\circ}$ longitudes). The geometric pattern of faulting may therefore be expected to exhibit a comparable geographic variation [Rosenburg et al., 2008; Beuthe, 2010].

\section{Discussion}

\subsection{Depth of Faulting}

[27] Lobate scarps are interpreted to be the surface expression of large thrust fault that deform the crust down to the brittle-ductile transition depth and have been utilized to estimate lithospheric properties [Watters et al., 2002]. Modeling the lobate scarp Discovery Rupes, Watters et al. [2002] estimate a fault depth of 35-40 km and interpret this as the depth of the BDT. From this, Nimmo and Watters [2004] estimate an effective elastic thickness of 25-30 km. Recent modeling results found similar values for lobate scarps profiled by the Mercury Laser Altimeter (MLA) during recent MESSENGER flybys [Ritzer et al., 2010]. From crosscutting relationships between lobate scarps and craters and embayment relations with smooth plains material, lobate scarp formation appears to have initiated after the emplacement of the intercrater plains ( $\sim$ Gyr ago) and prior to the end of smooth plains formation, continuing after the youngest smooth plains material was emplaced [Melosh and McKinnon, 1988; Watters and Nimmo, 2009]. Model results at the location of Discovery Rupes $\left(53^{\circ} \mathrm{S}, 37^{\circ} \mathrm{W}\right)$ are shown in Figure 8 for the approximate period of lobate scarp formation (the 500 Myr proceeding the end of late heavy bombardment). Lobate scarps modeled by Ritzer et al. [2010], although in the equatorial region, are located in a region $\left(\sim 60^{\circ} \mathrm{E}\right)$ with surface temperatures only slightly higher than Discovery Rupes. Many of the models employing a dry diabase crust rheology provide reasonable BDT depths during this period. A dry anorthite crust generally results in a BDT deeper than that implied by Discovery Rupes due to the stronger creep power law, but models that result in an early warm crust cannot be ruled out. None of the models employing a wet rheology achieved an adequate BDT depth, supporting a dry rheology for Mercury. This is at odds with evidence for pyroclastic eruptions observed in recent MESSENGER images [Head et al., 2008; Kerber et al., 2009]. Kerber et al. [2009] conclude that erupted magmas require a substantial volatile content to emplace pyroclastics to the observed distances from central vents. It is possible that volatiles were heterogeneously distributed, whereas the mercurian crust was mostly dry when lobate scarps were formed. Further observations, including estimates of $T_{\mathrm{e}}$, could possibly discern whether the mantle is characterized as being rich or poor in volatiles as dry and wet rheologies result in large differences in predicted $T_{\mathrm{e}}$ values.

\subsection{Implications for Surface Tectonics}

[28] Variations in compressive strength imply that the accommodation of radial contraction of Mercury as its interior cooled, manifest as lobate scarps, may preferentially occur in weaker, hotter equatorial quadrants, whereas a lithosphere modeled as a uniform spherical shell would be expected to produce an isotropic stress field at the surface, with no preferential orientation to the thrust faults. By measuring scarp orientations in spacecraft images from Mariner 10 and, more recently, MESSENGER, the effect of Mercury's heterogeneous insolation on its surface tectonics can be probed. However, this measurement can also contain 

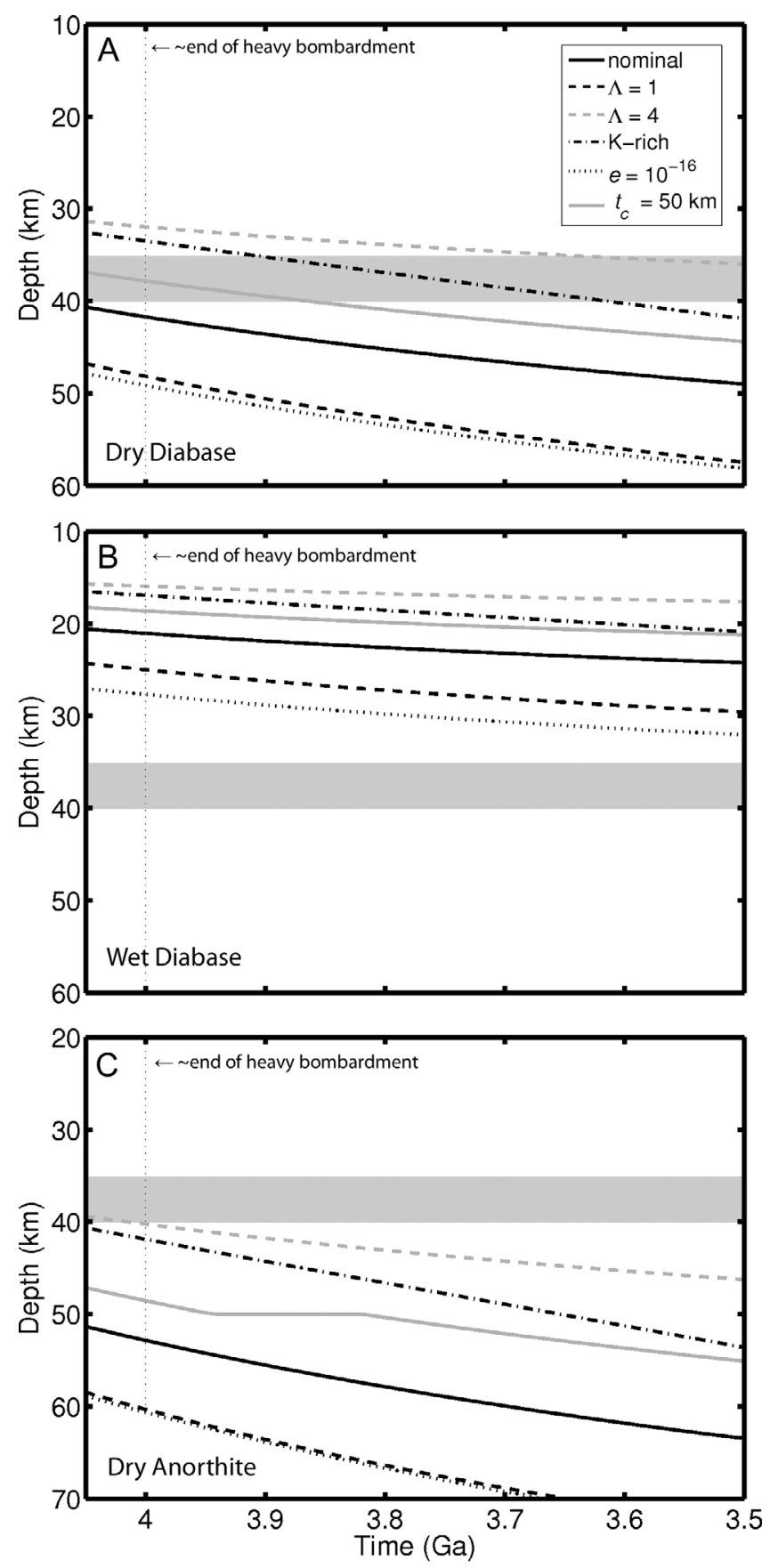

Figure 8. Results of the model at the location of Discovery Rupes $\left(53^{\circ} \mathrm{S}, 37^{\circ} \mathrm{W}\right)$ for $500 \mathrm{Myr}$ after the end of heavy bombardment ( $\sim$ Gyr BP), the approximate time of lobate scarp formation [Melosh and McKinnon, 1988]. Three rheologies are presented: (a) dry diabase crust, (b) wet diabase crust, and (c) dry anorthite crust. The estimated depth of Discovery Rupes by Watters et al. [2002], interpreted to represent the BDT depth, is $35-40 \mathrm{~km}$ (shaded). The effect of adjusting the parameters can be seen; however, the lack of constrains preludes eliminating many models. All models with a wet rheology result in excessively shallow DBT depths relative to that estimated for Discovery Rupes, while a dry anorthite crustal rheology generally results in a deeper BDT. illumination biases that emphasize some features and hide others depending on the geometry of the spacecraft flyby. Watters et al. [2004] analyzed these lighting biases within the Mariner 10 image set and attempted to correct for them by avoiding areas within $50^{\circ}$ of the subsolar point, where a high illumination angle renders subtle topographic features invisible. The remaining distribution of scarps failed a statistical test for uniformity [Fisher, 1990], suggesting that there is indeed a preferred orientation. The images provided by the three recent MESSENGER flybys were taken under different viewing conditions than the Mariner 10 images, causing some regions that had been viewed at high illumination angle in the earlier mission to be viewed at low illumination angles for the first time and revealing a variety of features that were not previously visible [Watters et al., 2009]. Though scarps mapped from both image sets do appear to be aligned roughly north-south [Rosenburg et al., 2008], the lighting biases are expected to still conceal features that have not been observed by either spacecraft. Nevertheless, a difference in both the orientation and the distribution (or magnitude) of faulting is expected to occur between the hot and cold poles of Mercury's surface, and this difference may be detectable using future images as well as altimetry data soon to be collected by MESSENGER's laser altimeter, MLA, which will avoid biases due to illumination angle.

\section{Conclusions}

[29] The lateral variation in thermal structure and therefore lithospheric strength, resulting from the differential insolation of Mercury's surface, has been demonstrated to be substantial. For example, by the end of late heavy bombardment ( 4 Gyr) we find a difference in BDT depth of $11 \mathrm{~km}$ and $T_{\text {mech }}$ of $15 \mathrm{~km}$ between the hot and cold equatorial thermal poles with a corresponding strength increase of $1.6 \times$ and a difference between the hot equatorial pole and the latitudes $\pm 90^{\circ}$ of 30 and $43 \mathrm{~km}$ for the BDT depth and $T_{\text {mech }}$, respectively, with a corresponding strength increase of $3.0 \times$ for our nominal model. The magnitude of the lateral heterogeneity grows with time and is accentuated by the differential timing of the mantle contribution to the lithosphere strength. Variations in present-day BDT depths and $T_{\text {mech }}$ increase to 18 and $30 \mathrm{~km}$, respectively, between the hot and cold equatorial poles and 77 and $76 \mathrm{~km}$, respectively, between the hot equatorial pole and latitudes $\pm 90^{\circ}$. This corresponds to strength differences of $1.8 \times$ between the hot and cold equatorial poles and $5.2 \times$ between the hot equatorial pole and latitudes $\pm 90^{\circ}$. A comparison with estimated fault depths of lobate scarps demonstrates that wet rheologies for the crust and mantle are inconsistent with the estimated BDT depth implying Mercury's interior is volatilepoor in character.

[30] Although many of the parameters of the model are poorly constrained, the overall heterogeneity remains regardless of the choice of parameters. Future exploration by the MESSENGER and BepiColumbo missions will provide further details about the planet and allow for the development a more detailed understanding of the lithospheric structure and provide useful constraints on the relevant parameters in this model. The latitudinal surface temperature variation experienced by Mercury is not unlike that of the 
Earth's Moon presently and thus one should expect an analogous latitude dependence on lithospheric strength to have developed over time on the Moon as well.

[31] Acknowledgments. We wish to thank David A. Paige, the associate editor of JGR-Planets, and two anonymous reviewers for their helpful comments and suggestions that resulted in an improved manuscript. This work was funded by the National Science Foundation Division of Earth Sciences (EAR) and the Astronomy and Astrophysics Research Grants program (AST-0709151). J. R. was supported by a contract Ramón y Caja cofinanced from the Ministerio de Ciencia e Innovación of Spain and the Fondo Social Europeo (ESF).

\section{References}

Aharonson, O., M. T. Zuber, and S. C. Solomon (2004), Crustal remanence in an internally magnetized nonuniform shell: A possible source for Mercury's magnetic field?, Earth Planet. Sci. Lett., 218, 261-268.

Anderson, W. W., and T. J. Ahrens (1994), An equation of state for liquid iron and implications for the Earth's core, J. Geophys. Res., 99, 4273-4284.

Anderson, J. D., R. F. Jurgens, E. L. Lau, M. A. Slade, and G. Schubert (1996), Shape and orientation of mercury from radar ranging data Icarus, 124, 690-697.

Anderson, S., and R. E. Grimm (1998), Rift processes at the Valles Marineris, Mars: Constraints from gravity on necking and rate-depending strength evolution, J. Geophys. Res., 103(E5), 11,113-11,124, doi:10.1029/ 98JE00740.

Anselmi, A., and G. E. N. Scoon (2001), BepiColombo: ESA's Mercury Cornerstone mission, Planet. Space Sci., 49, 1409-1420.

Beuthe, M. (2010), East-west faults due to planetary contraction, Icarus, 209, 795-817, doi:10.1016/j.icarus. 2010.04.019.

Blewett, D. T., B. R. Hawke, and P. G. Lucey (2002), Lunar pure anorthosite as a spectral analog for Mercury, Meteorit. Planet. Sci., 37, 1245-1254.

Blundy, J., and B. Wood (2003), Partitioning of trace elements between crystals and melts, Earth Planet. Sci. Lett., 210, 383-397.

Boehler, R. (1996), Experimental constraints on melting conditions relevant to core formation, Geochim. Cosmochim. Acta, 60, 1109-1112.

Breuer, D., and T. Spohn (2003), Early plate tectonics versus single-plate tectonics on Mars: Evidence from magnetic field history and crust evolution, J. Geophys. Res., 108(E7), 5072, doi:10.1029/2002JE001999.

Breuer, D., S. A. Hauck II, M. Buske, M. Pauer, and T. Spohn (2007), Interiorevolution of Mercury, Space Sci. Rev., 132, 229-260.

Burov, E. B., and M. Diament (1992), Flexure of the continental lithosphere with multilayered rheology, Geophys. J. Int., 109, 449-468.

Burov, E. B., and M. Diament (1995), The effective elastic thickness $\left(T_{\mathrm{e}}\right)$ of continental lithosphere: What does it really mean?, J. Geophys. Res., 100(B3), 3905-3927, doi:10.1029/94JB02770.

Byerlee, J. D. (1968), Brittle ductile transition in rocks, J. Geophys. Res., 73(14), 4741-4650, doi:10.1029/JB073i014p04741.

Byerlee, J. D. (1978), Friction of rocks, Pure Appl. Geophys., 116, 615-626.

Cameron, A. G. W., B. Fegely Jr., W. Benz, and W. L. Slattery (1988) The strange density of Mercury: Theoretical considerations, in Mercury, edited by F. Vilas, C. Chapman, and M. Matthews, pp. 692-708, Univ. of Ariz. Press, Tuscon.

Caristan, Y. (1982) The transition from high temperature creep to fracture in Maryland diabase, J. Geophys. Res., 87(B8), 6781-6790, doi:10.1029/ JB087iB08p06781.

Chen, B., J. Li, and S. A. Hauck II (2008), Non-ideal liquidus curve in the Fe-S system and Mercury's snowing core, Geophys. Res. Lett., 35, L07201, doi:10.1029/2008GL033311.

Chopra, P. N., and M. S. Paterson (1984), The role of water in the deformation of dunite, J. Geophys. Res., 89(B9), 7861-7876, doi:10.1029/ JB089iB09p07861.

Davaille, A., and C. Jaupart (1993), Transient high Rayleigh number thermal convection with large viscosity variations, J. Fluid Mech., 253, 141-166.

Denevi, B. W., et al. (2009), The evolution of Mercury's crust: A global perspective from MESSENGER, Science, 324, 613-618.

Fegley, B., Jr., and A. G. W. Cameron (1987), A vaporization model for iron/silicate fractionation in the Mercury protoplanet, Earth Planet. Sci. Lett., 82, 207-222.

Fei, Y. W., C. T. Prewitt, H. K. Mao, and C. M. Bertka (1995), Structure and density of $\mathrm{Fe}$ at high-pressure and high-temperature and the internal structure of Mars, Science, 268, 1892-1894.

Fei, Y. W., C. M. Bertka, and L. W. Finger (1997), High-pressure iron sulfur compound, Fe3S2, and melting relations in the Fe-FeS system, Science, 275, 1621-1623.
Fei, Y. W., J. Li, C. M. Bertka, and C. T. Prewitt (2000), Structure type and bulk modulus of Fe3S, a new iron-sulfur compound, Am. Mineral., 85 , $1830-1833$

Fisher, N. I. (1990), Statistical Analysis of Circular Data, Cambridge Univ. Press, Cambridge, U. K.

Grard, R., and A. Balogh (2001), Returns to Mercury: Science and mission objectives, Planet. Space Sci., 49, 1395-1407.

Grasset, O., and E. M. Parmentier (1998), Thermal convection in a volumetrically heated, infinite Prandtl number fluid with strongly temperaturedependent viscosity: Implications for planetary thermal evolution, J. Geophys. Res., 103(B8), 18,171-18,181, doi:10.1029/98JB01492.

Hauck, S. A., A. J. Dombard, R. J. Phillips, and S. C. Solomon (2004), Internal and tectonic evolution of Mercury, Earth Planet. Sci. Lett., 222, 728-731.

Hauri, E. H., T. P. Wagner, and T. L. Grove (1994), Experimental and natural partitioning of $\mathrm{Th}, \mathrm{U}, \mathrm{Pb}$ and other trace elements between garnet, clinopyroxene and basaltic melts, Chem. Geol., 117, 149-166.

Head, J. W., et al. (2008), Volcanism on Mercury: Evidence from the first MESSENGER flyby, Science, 321, 69-72.

Hikida, H., and M. A. Wieczorek (2007), Crustal thickness of the Moon: New constraints from gravity inversions using polyhedral shape models, Icarus, 192, 150-166.

Ishihara, Y., S. Goossens, K. Matsumoto, H. Noda, H. Araki, N. Namiki, H. Hanada, T. Iwata, S. Tazawa, and S. Sasaki (2009), Crustal thickness of the Moon: Implications for farside basin structures, Geophys. Res. Lett., 36, L19202, doi:10.1029/2009GL039708.

Kerber, L., J. W. Head, S. C. Solomon, S. L. Murchie, D. T. Blewett, and L. Wilson (2009), Explosive volcanic eruptions on Mercury: Eruption conditions, magma volatile content, and implications for interior volatile abundances, Earth Planet. Sci. Lett., 285, 263-271.

Lawrence, D. J., W. C. Feldman, J. O. Goldsten, T. J. McCoy, D. T. Blewett, W. V. Boynton, L. G. Eveans, L. R. Nittler, E. A. Rhodes, and S. C. Solomon (2010), Identification and measurement of neutronabsorbing elements on Mercury's surface, Icarus, 209, 195-209.

Lodders, K., and B. Fegely Jr. (1998), The Planetary Scientist's Companion, 371 pp., Oxford Univ. Press, New York.

Mackwell, S. J., Q. Bai, and D. L. Kohlstedt (1990), Rheology of olivine and the strength of the lithosphere, Geophys. Res. Lett., 17(1), 9-12, doi:10.1029/GL017i001p00009.

Mackwell, S. J., M. E. Zimmerman, and D. L. Kohlstedt (1998), Hightemperature deformation of dry diabase with application to tectonics on Venus, J. Geophys. Res., 103(B1), 975-984, doi:10.1029/97JB02671.

McGovern, P. J., S. C. Solomon, D. E. Smith, M. T. Zuber, M. Simons, M. A. Wieczorek, R. J. Phillips, G. A. Neumann, O. Aharonson, and J. W. Head (2002), Localized gravity/topography admittance and correlation spectra on Mars: Implications for regional and global evolution, J. Geophys. Res., 107(E12), 5136, doi:10.1029/2002JE001854.

McKinnon, W. B. (1981), Application of ring tectonic theory to Mercury and other solar system bodies, in Multi-Ring Basins, edited by P. H. Schultz and R. B. Merrill, Proc. Lunar Planet. Sci., 12A, 259-273.

McNutt, M. K. (1984), Lithospheric flexure and thermal anomalies, J. Geophys. Res., 89(B13), 11,180-11,194, doi:10.1029/JB089iB13p11180.

Melosh, H. J., and W. B. McKinnon (1988), The tectonics of Mercury, in Mercury, edited by F. Vilas, C. Chapman, and M. Matthews, pp. 374-400, Univ. of Ariz. Press, Tuscon.

Mitchell, D. L., and I. De Pater (1994), Microwave imaging of Mercury's thermal emission at wavelengths from 0.3 to $20.5 \mathrm{~cm}$, Icarus, $110,2-32$.

Moresi, L.-N., and V. S. Solomatov (1995), Numerical investigation of 2D convection with extremely large viscosity variations, Phys. Fluid, 7, 2154-2162.

Neumann, G. A., M. T. Zuber, M. A. Wieczorek, P. J. McGovern, F. G. Lemoine, and D. E. Smith (2004), Crustal structure of Mars from gravity and topography, J. Geophys. Res., 109, E08002, doi:10.1029/ 2004JE002262.

Nimmo, F. (2002), Constraining the crustal thickness on mercury from viscous topographic relaxation, Geophys. Res. Lett., 29(5), 1063 doi:10.1029/2001GL013883.

Nimmo, F., and D. J. Stevenson (2000), Influence of early plate tectonics on the thermal evolution and magnetic field of Mars, J. Geophys. Res., 105(E5), 11,969-11,979, doi:10.1029/1999JE001216.

Nimmo, F., and T. R. Watters (2004), Depth of faulting on Mercury: Implications for heat flow and crustal and effective elastic thickness, Geophys. Res. Lett., 31, L02701, doi:10.1029/2003GL018847.

Nimmo, F., G. D. Price, J. Brodholt, and D. Gubbins (2004), The influence of potassium on core and geodynamo evolution, Geophys. J. Int., 156 , 363-376.

Philpotts, J. A., and C. C. Schnetzler (1970), Phenocryst-matrix partition coefficients for $\mathrm{K}, \mathrm{Rb}, \mathrm{Sr}$, and $\mathrm{Ba}$, with applications to anorthosite and basalt genesis, Geochim. Cosmochim. Acta, 34, 307-322. 
Prockter, L. M., et al. (2010), Evidence for young volcanism on Mercury from the third MESSENGER flyby, Science, 329, 668-671.

Ranalli, G. (1994), Nonlinear flexure and equivalent mechanical thickness of the lithosphere, Tectonophysics, 240, 107-114.

Ranalli, G. (1997) Rheology of the lithosphere in space and time, Geol. Soc. Spec. Publ., 121, 19-37.

Ranalli, G., and D. C. Murphy (1987), Rheological stratification of the lithosphere, Tectonophysics, 132, 281-295.

Redmond, H. L., and S. D. King (2007), Does mantle convection currently exist on Mercury?, Phys. Earth Planet. Inter., 164, 221-231.

Reese, C. C., V. S. Solomatov, and L.-N. Moresi (1999), Non-Newtonian stagnant lid convection and magmatic resurfacing on Venus, Icarus, 139, 67-80.

Reese, C. C., V. S. Solomatov, and J. R. Baumgardner (2005), Scaling laws for time-dependent stagnant lid convection in a spherical shell, Phys. Earth Planet. Inter., 149, 361-370.

Regenauer-Lieb, K., D. A. Yuen, and J. Branlund (2001), The initiation of subduction: Critically by addition of water?, Science, 294, 578-580.

Ritzer, J. A., S. A. Hauck II, O. S. Barnouin, S. C. Solomon, and T. R. Watters (2010), Mechanical structure of Mercury's lithosphere from MESSENGER observations of lobate scarps, Lunar Planet. Sci., XLI, abstract 2122

Rosenburg, M. A., J. Williams, and O. Aharonson (2008), The effect of heterogeneous lithospheric structure on surface stress and tectonics on Mercury, Eos Trans. $A G U, 89(53)$, Fall Meet. Suppl., Abstract U21A0017.

Ruiz, J., P. J. McGovern, and R. Tejero (2006), The early thermal and magnetic state of the cratered highlands of Mars, Earth Planet. Sci. Lett., 241 , $2-10$.

Ruiz, J., C. Fernández, D. Gomez-Ortiz, J. M. Dohm, V. López, and R. Tejero (2008), Ancient heat flow, crustal thickness, and lithospheric mantle rheology in the Amenthes region, Mars, Earth Planet. Sci. Lett., $270,1-12$.

Ruiz, J., J.-P. Williams, J. M. Dohm, C. Fernández, and V. López (2009), Ancient heat flow and crustal thickness at Warrego rise, Thaumasia highlands, Mars: Implications for a stratified crust, Icarus, 203, 47-57.

Rybacki, E., and G. Dresen (2000), Dislocation and diffusion creep of synthetic anorthite aggregates, J. Geophys. Res., 105(B11), 26,017-26,036, doi:10.1029/2000JB900223.

Schubert, G., M. N. Ross, D. J. Stevenson, and T. Spohn (1988), Mercury's thermal history and the generation of its magnetic field, in Mercury, edited by F. Vilas, C. Chapman, and M. Matthews, pp. 429-460, Univ. of Ariz. Press, Tuscon.

Schubert, G., D. L. Turcotte, and P. Olson (2001), Mantle Convection in the Earth and Planets, Cambridge Univ. Press, Cambridge, U. K.

Smith, D. E., et al. (2010), The equatorial shape and gravity field of Mercury from MESSENGER flybys 1 and 2, Icarus, 209, 88-100, doi:10.1016/j.icarus.2010.04.007.

Solomatov, V. S. (1995), Scaling of temperature-dependent and stressdependent viscosity convection, Phys. Fluids, 7, 266-274.

Solomatov, V. S., and L.-N. Moresi (1996), Stagnant lid convection on Venus, J. Geophys. Res., 101(E2), 4737-4753, doi:10.1029/95JE03361.

Solomatov, V. S., and L.-N. Moresi (2000), Scaling of time-dependent stagnant lid convection: Application to small-scale convection on Earth and other terrestrial planets, J. Geophys. Res., 105(B9), 21,795-21,817, doi:10.1029/2000JB900197.

Solomon, S. C., et al. (2001), The MESSENGER mission to Mercury: Scientific objectives and implementation, Planet. Space. Sci., 49, 1445-1465.
Solomon, S. C., et al. (2008), Return to Mercury: A global perspective on MESSENGER's first Mercury flyby, Science, 321, 59-62.

Strom, R. G., N. J. Trask, and J. E. Guest (1975), Tectonism and volcanism on Mercury, J. Geophys. Res., 80(17), 2478-2507, doi:10.1029/ JB080i017p02478.

Tesauro, M., M. K. Kaban, S. A. P. L. Cloeting, N. J. Hardebol, and F. Beekman (2007), 3D strength and gravity anomalies of the European lithosphere, Earth Planet. Sci. Lett., 263, 56-73.

Trompert, R. A., and U. Hansen (1998), On the Rayleigh numberdependence of convection with a strongly temperature-dependent viscosity, Phys. Fluids, 10, 351-360.

Vasavada, A. R., D. A. Paige, and S. E. Wood (1999), Near-surface temperatures on Mercury and the Moon and the stability of polar ice deposits, Icarus, 141, 179-193.

Watters, T. R., and F. Nimmo (2009), The tectonics of Mercury, in Planetary Tectonics, edited by T. R. Watters and R. A. Schultz, pp. 15-80, Cambridge Univ. Press, Cambridge, U. K.

Watters, T. R., R. A. Schultz, M. S. Robinson, and A. C. Cook (2002), The mechanical and thermal structure of Mercury's early lithosphere, Geophys. Res. Lett., 29(11), 1542, doi:10.1029/2001GL014308.

Watters, T. R., M. S. Robinson, C. R. Bina, and P. D. Spudis (2004), Thrust faults and the global contraction of Mercury, Geophys. Res. Lett., 31, L04701, doi:10.1029/2003GL019171.

Watters, T. R., S. C. Solomon, M. S. Robinson, J. W. Head, S. L. André, S. A. Hauck II, and S. L. Murchie (2009), The tectonics of Mercury: The view after MESSENGER's first flyby, Earth Planet. Sci. Lett., 285, 283-296.

Watts, A. B. (2001), Isostasy and Fluxure of the Lithosphere, Cambridge Univ. Press, New York.

Watts, A. B., and E. B. Burov (2003), Lithospheric strength and its relation to the elastic and seismogenetic layer thickness, Earth Planet. Sci. Lett., 213, 113-131.

Wieczorek, M. A., and M. T. Zuber (2004), Thickness of the Martian crust: Improved constraints from geoid-to-topography ratios, J. Geophys. Res. 109, E01009, doi:10.1029/2003JE002153.

Wieczorek, M. A., et al. (2006) The constitution and structure of the lunar interior, in New Views of the Moon, Rev. Min. Geochem., vol. 60, edited by B. J. Jolliff et al., pp. 221-364, Mineral. Soc. Am., Chantilly, Va.

Williams, J.-P., and F. Nimmo (2004), Thermal evolution of the Martian core: Implications for an early dynamo, Geology, 32, 97-100.

Williams, J.-P., O. Aharonson, and F. Nimmo (2007), Powering Mercury's dynamo, Geophys. Res. Lett., 34, L21201, doi:10.1029/2007GL031164.

Zuber, M. T., et al. (2000), Internal structure and early thermal evolution of Mars from Mars Global Surveyor topography and gravity, Science, 287 1788-1793.

Zuber, M. T., et al. (2010), Accommodation of lithospheric shortening on Mercury from altimetric profiles of ridges and lobate scarps measured during MESSENGER flybys 1 and 2, Icarus, 209, 247-255, doi:10.1016/j.icarus.2010.02.026.

O. Aharonson, M. A. Rosenburg, and J.-P. Williams, Division of Geological and Planetary Sciences, California Institute of Technology, MC 150-21, Pasadena, CA 91125-2100, USA. (jpierre@gps.caltech.edu)

R. J. Phillips, Planetary Science Directorate, Southwest Research Institute, Boulder, CO 80302, USA.

J. Ruiz, Departamento de Geodinámica, Facultad de Ciencias Geológicas, Universidad Complutense de Madrid, E-28040 Madrid, Spain. 